\title{
Toll-like receptor 4 gene polymorphisms and susceptibility to colorectal cancer: a meta-analysis and review
}

\author{
Wang Yan Sheng, Zhang Yong, Zhu Yun, Hu Hong, Luo Lin Hai
}

The People's Hospital of Yuxi, Yuxi, China

Submitted: 26 February 2014

Accepted: 9 May 2014

Arch Med Sci 2015; 11, 4: 699-707

DOI: 10.5114 /aoms.2015.53288

Copyright $\odot 2015$ Termedia \& Banach

\begin{abstract}
Introduction: Many case-control studies have investigated the association between toll-like receptor 4 (TLR4) Asp299Gly and Thr399lle polymorphisms and risk of colorectal cancer (CRC). However, published data are still conflicting.

Material and methods: A systematic search was conducted in the electronic databases of PubMed, MEDLINE, EMBASE, Web of Science and CNKI between 2000 and 2014. The associations between TLR4 polymorphisms and CRC susceptibility were assessed by pooled odds ratios (ORs) and $95 \%$ confidence intervals $(95 \% \mathrm{Cl})$ in fixed or random effects models.

Results: In total nine case-control studies were identified in this meta-analysis. For TLR4 Asp299Gly polymorphism, 9 studies included 1198 cases and 1290 controls. The GG genotype carriers had higher risk for developing CRC than $\mathrm{AA}+\mathrm{GA}$ genotype carriers $(\mathrm{OR}=1.95,95 \% \mathrm{Cl}: 1.00-3.77, p=0.05)$. No association was found in other genetic models $(p>0.05)$. Analysis stratified by ethnicity showed no association in any genetic models among the Asian or Caucasian population. For TLR4 Thr399lle polymorphism, 6 studies contained 619 cases and 632 controls. The overall analysis showed significantly increased risk in TT homozygote carriers compared to CC homozygote $(\mathrm{OR}=4.99$, $95 \% \mathrm{Cl}: 1.41-17.65, p=0.01)$ and C carriers $(\mathrm{TC}+\mathrm{CC})(\mathrm{OR}=4.50,95 \% \mathrm{Cl}$ : $1.27-15.87, p=0.02)$. In terms of analyses stratified by race, a significant association was found in each genetic model among the Asian population, rather than the Caucasian group.

Conclusions: The GG homozygote carriers of TLR4 Asp299Gly and TT homozygote carriers of TLR4 Thr399lle polymorphisms might be correlated with an increased risk of CRC, suggesting they may serve as genetic risk factors for CRC.
\end{abstract}

Key words: colorectal carcinoma, toll-like receptor 4, polymorphism, metaanalysis.

\section{Introduction}

Colorectal carcinoma (CRC) is one of the primary causes of cancer death throughout the world and is still a major public health problem. Clinical studies indicate that the host immune system plays a key role in the development and progression of CRC [1]. According to global cancer statistics, it is the third most commonly diagnosed cancer in males and the second in females, with over 1.2 million new cancer cases and 608,700 deaths estimated to have occurred in 2008 [2]. Its incidence

\author{
Corresponding author: \\ Luo Lin Hai \\ The People's Hospital of Yuxi \\ No.21 Nieer Road \\ 653100 Yuxi \\ Hongta District, China \\ Phone: +86 08772014046 \\ E-mail: Luolinhai_L@163.com
}


rates continue to increase in economically transitioning countries [3]. Moreover, a large portion of successfully treated CRC patients develop a recurrence or metastasis within 5 years of diagnosis [4]. Hence, there is a real need to develop targeted prevention and early detection programs to reverse this situation.

Both environmental and genetic factors contribute to the tumorigenesis of CRC. Genome-wide association studies have shown that inherited genetic variation can contribute to CRC prognosis [5], and so far have successfully identified 20 susceptible single nucleotide polymorphisms (SNPS) in 18 risk loci for CRC, among which the toll-like receptor (TLR) gene polymorphisms have been highlighted [6]. TLRs are pattern-recognition receptors (PRRs) which have emerged as central regulators of intestinal homeostasis and CRC [7], and mediate the innate immune response to LPS challenge [8]. TLR4 is one of the major TLRs, and has been actively investigated in inflammation and cancer. It is involved in the regulation of inflammatory reactions and activation of the adaptive immune response to eliminate infectious pathogens and cancer debris $[9,10]$. TLR4 is located on chromosome 9q32-q33, and contains four exons. There are two SNPs in TLR4 exon 3; one is an A/G substitution at 896 base pairs (bp), and the other is a C/T substitution at $1196 \mathrm{bp}$. Research has shown that TLR4 A896G has a protective effect on high house dust mite allergen exposure against specific sensitization [11]. A previous meta-analysis demonstrated that TLR4 polymorphisms are associated with gastric carcinogenesis and Crohn's disease [12, 13], while a recent study proved that these polymorphisms were not involved in the development of autoimmune diseases [14]

Recent studies suggest that gene variants in TLR4, which affect the extracellular domain of the receptor and may cause decreased ligand recognition [15], are critical for CRC susceptibility. However, the results remained inconsistent rather than conclusive. Therefore, we conducted this meta-analysis on all eligible published case-control studies to establish a relatively comprehensive picture of the relationship between these genetic variants and $C R C$ risk.

\section{Material and methods}

\section{Identification and eligibility of relevant studies}

We searched for relevant papers published between 2000 and 2014 using the electronic databases of PubMed, MEDLINE, EMBASE, Web of Science and CNKI (China National Knowledge Infrastructure) with the following search terms: "toll-like receptor 4 or TLR4", "polymorphism", "variant", "colorectal carcinoma or colorectal cancer" and "colon cancer" as well as their combinations. The corresponding Chinese terms were used in the Chinese library. No language restric tions were applied. All studies matching the eligibility criteria were retrieved, and references of the retrieved articles were also screened for original studies.

\section{Criteria for article screening}

Studies included had to meet all the following criteria: 1) case-control or cohort association studies; 2) evaluated the relationship of TLR4 (Asp299Gly and Thr399lle) polymorphisms with CRC risk; 3) genotype distributions in the cases and controls were available for estimating the odds ratio (OR) with its $95 \%$ confidence interval $(\mathrm{Cl})$; and 4) the distribution of genotypes in the control group was consistent with Hardy-Weinberg equilibrium (HWE) [16].

The major exclusion criteria were: 1) only case population; 2) reviews, conference abstracts in which the genotype frequencies were not extractable; 3 ) the study did not have the outcomes of a comparison report; and 4) duplicate of previous articles.

\section{Data extraction}

All of the data were independently abstracted in duplicate by two authors using a data abstraction form to retrieve information on first author, year of publication, country, ethnicity, sample size, genotyping method, and the genotype frequencies in the cancer cases and controls. Disagreements between authors were resolved by consensus.

\section{Statistical analysis}

The crude OR and its $95 \% \mathrm{Cl}$ were used to assess the strength of the association between the TLR4 polymorphisms with the risk of CRC. The $Z$ test was employed to determine the significance of the pooled ORs, and a $p$ value less than 0.05 was considered statistically significant. This study examined the association between TLR4 Asp299Gly and Thr399lle polymorphisms and CRC risk compared with that for the per-allele model (G vs. A for Asp299Gly, T vs. C for Thr399lle), dominant model (GG + GA vs. AA for Asp299Gly, TT + TC vs. CC for Thr399lle), recessive model (GG vs. GA + AA for Asp299Gly, TT vs. TC + CC for Thr399lle), and additive model (GG vs. AA for Asp299Gly, TT vs. CC for Thr399lle). To evaluate whether the association showed any ethnicity-specific effects, we analyzed the data for subgroups defined by ethnicity. The heterogeneity of the included articles was evaluated using Cochran's $Q$ test and $P^{2}$ statistics. $P$-values less than 0.1 and $l^{2}$ less than $50 \%$ were considered 
to be statistically significant. When a significant heterogeneity existed across the included studies ( $p<0.1$ and $R^{2}>50 \%$ ), the random effect model was used. When there was no significant heterogeneity across the included studies ( $p>0.1$ and $\left.R^{2}<50 \%\right)$, the fixed effect model was used. To assess whether our results were substantially influenced by the presence of any individual study, we conducted a sensitivity analysis by systematically removing each study and recalculating the significance of the result. Begg's funnel plot was used to examine the publication bias. Analyses were carried out using Review Manager 5.2 (The Cochrane Collaboration). All tests were two-sided.

\section{Results}

\section{Characteristics of studies}

The electronic database search identified 213 references. Of those, 159 records excluded for duplication and 54 articles were judged potentially relevant. Following screening of titles and $a b$ stracts for relevance, 31 full-text articles were comprehensively assessed against inclusion criteria. Overall, a total of 9 prospective cohort studies (7 in English and 2 in Chinese) containing 1448 CRC cases and 1640 controls were finally included in this review. Figure 1 shows the study flow.

Of the nine included articles, one was from Malaysia [17], one was from Tunisia [18], one was from Portugal [19], three were from China [20-22], one was from Croatia [23], one was from Russian [24] and one was from Spain [25]. The major characteristics of the eligible publications are reported in Table I. The genotype frequencies are listed in Table II.

\section{Association of TLR4 Asp299Gly polymorphism and CRC risk}

The evaluation of the association between these two polymorphisms and CRC risk is present-

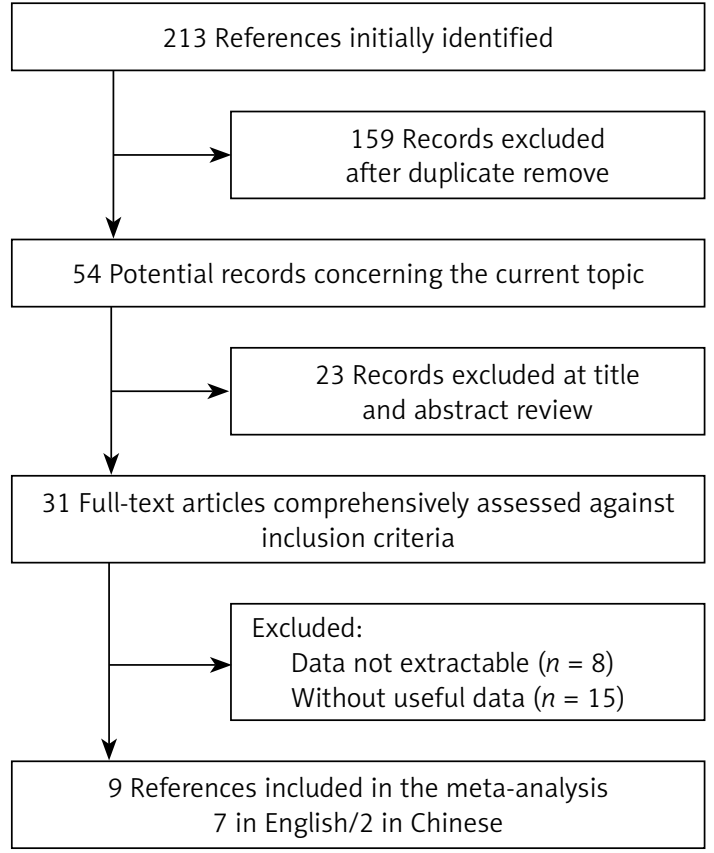

Figure 1. Flow chart of literature screening

ed in Table III. For TLR4 Asp299Gly polymorphism, a total of 9 studies including 1408 cancer cases and 1553 controls were selected in our meta-analysis. No significant heterogeneity was found among the included studies, and the fixed-effect model was chosen to analyze the data $(p>0.1)$. Overall, the frequency of $\mathrm{G}$ is higher in CRC than that in the healthy controls (6.8\% vs. $5.3 \%$ ). As shown in Figure 2, we found that GG homozygote carriers in the recessive model have an increased risk of CRC compared with A allele carriers (OR $=1.95$, 95\% Cl: 1.00-3.77, $p=0.05$ ) in a fixed-effect model. No association was found in other genetic models (G vs. $A: O R=1.19,95 \% \mathrm{Cl}: 0.95-1.50, p=0.14$; $\mathrm{GG}+\mathrm{GA}$ vs. $\mathrm{AA}: \mathrm{OR}=1.20,95 \% \mathrm{Cl}: 0.94-1.54$, $p=0.14$; GG vs. AA: $\mathrm{OR}=1.27,95 \% \mathrm{Cl}: 0.52-3.15$, $p=0.60)$. In an analysis stratified by ethnicity, no

Table I. Main characteristics of studies included in this meta-analysis

\begin{tabular}{|lcccccc|}
\hline First author & Year & Country & Ethnicity & Cases & Controls & Genotyping method \\
\hline Boraska Jelavic & 2006 & Croatia & Caucasian & 89 & 88 & PCR-RFLP \\
\hline Guo & 2006 & China & Asian & 110 & 160 & PCR \\
\hline Landi & 2006 & Spain & Caucasian & 282 & 269 & PCR-TaqMan \\
\hline Davoodi & 2011 & Malaysia & Asian & 60 & 50 & PCR-RFLP \\
\hline Yang & 2011 & China & Asian & 102 & 87 & PCR sequencing \\
\hline Dai & 2012 & China & Asian & 268 & 268 & PCR \\
\hline Omrane & 2013 & Tunisia & Caucasian & 100 & 140 & PCR \\
\hline Pimentel-Nunes & 2013 & Portugal & Caucasian & 193 & 278 & PCR \\
\hline Kutikhin & 2014 & Russian & Caucasian & 244 & 300 & PCR
\end{tabular}


Table II. Distributions of TLR4 (Asp299Gly and Thr399lle) polymorphism genotypes and alleles among cancer patients and controls

\begin{tabular}{|c|c|c|c|c|c|c|c|c|c|c|}
\hline \multirow{3}{*}{$\begin{array}{l}\text { Author } \\
\text { Asp299Gly }\end{array}$} & \multicolumn{6}{|c|}{ Genotypes } & \multicolumn{4}{|c|}{ Alleles } \\
\hline & \multicolumn{3}{|c|}{ Cases } & \multicolumn{3}{|c|}{ Controls } & \multicolumn{2}{|c|}{ Cases } & \multicolumn{2}{|c|}{ Controls } \\
\hline & $\mathrm{AA}$ & $\mathrm{GA}$ & GG & $\mathrm{AA}$ & GA & GG & A & G & A & G \\
\hline Boraska Jelavic & 77 & 10 & 2 & 84 & 4 & 0 & 164 & 14 & 220 & 0 \\
\hline Guo & 110 & 0 & 0 & 160 & 0 & 0 & 220 & 0 & 320 & 0 \\
\hline Landi & 251 & 31 & 0 & 232 & 37 & 0 & 533 & 31 & 501 & 37 \\
\hline Davoodi & 58 & 2 & 0 & 50 & 0 & 0 & 118 & 2 & 100 & 0 \\
\hline Yang & 96 & 4 & 2 & 84 & 2 & 1 & 196 & 8 & 170 & 4 \\
\hline Dai & 219 & 44 & 5 & 228 & 38 & 2 & 482 & 54 & 494 & 42 \\
\hline Omrane & 87 & 13 & 0 & 120 & 18 & 2 & 187 & 13 & 258 & 22 \\
\hline Pimentel-Nunes & 169 & 0 & 15 & 186 & 0 & 5 & & & & \\
\hline Kutikhin & 173 & 40 & 0 & 258 & 39 & 3 & 386 & 40 & 555 & 45 \\
\hline Thr399lle & $\mathrm{CC}$ & $\mathrm{TC}$ & TT & CC & $\mathrm{TC}$ & TT & C & $T$ & C & $T$ \\
\hline Boraska Jelavic & 77 & 12 & 0 & 82 & 5 & 0 & 166 & 12 & 169 & 5 \\
\hline Davoodi & 58 & 2 & 0 & 50 & 0 & 0 & 118 & 2 & 100 & 0 \\
\hline Yang & 92 & 8 & 2 & 86 & 1 & 0 & 192 & 12 & 173 & 1 \\
\hline Dai & 182 & 78 & 8 & 214 & 52 & 2 & 442 & 94 & 480 & 56 \\
\hline Omrane & 94 & 6 & 0 & 123 & 17 & 0 & 194 & 6 & 263 & 17 \\
\hline Kutikhin & 195 & 36 & 2 & 255 & 45 & 0 & 426 & 40 & 555 & 45 \\
\hline
\end{tabular}

association was found in any genetic models among the Asian or Caucasian population (Table III).

\section{Association of TLR4 Thr399lle polymorphism and CRC risk}

For Thr399lle polymorphism, 6 articles including 852 CRC cases and 932 controls were retrieved in our study. The overall analysis showed significant increased risk in TT homozygotes carriers compared to CC homozygotes in the additive model $(\mathrm{OR}=4.99,95 \% \mathrm{Cl}: 1.41-17.65, p=0.01)$ and $\mathrm{C}$ allele carriers in the recessive model (TC + CC) $(\mathrm{OR}=4.50,95 \% \mathrm{Cl}: 1.27-15.87, p=0.02)$ (Figures 3 and 4). No association was observed in the dominant model $(\mathrm{OR}=1.51,95 \% \mathrm{Cl}: 0.85-2.67$, $p=0.16$ ) and allelic model (T vs. C: $\mathrm{OR}=1.52$, $95 \% \mathrm{Cl}: 0.88-2.61, p=0.13$ ) (Figures 5 and 6). When evaluating the effect of the polymorphism by ethnicity, we found a significant association in all genetic models among the Asian population (T vs. C: $\mathrm{OR}=2.04,95 \% \mathrm{Cl}: 1.45-2.88, p<0.0001 ; \mathrm{TT}+\mathrm{TC}$ vs. $\mathrm{CC}: \mathrm{OR}=2.10,95 \% \mathrm{Cl}: 1.44-3.06, p=0.0001$; TT vs. TC + CC: $O R=4.15,95 \% \mathrm{Cl}: 1.04-16.62$, $p=0.04 ;$ TT vs. CC: $\mathrm{OR}=4.70,95 \% \mathrm{Cl}: 1.17-18.88$, $p=0.03$ ) in a fixed-effect model, while no relationship was found among the Caucasian population $(p>0.05)$.

\section{Sensitivity analyses and publication bias}

A single study included in the meta-analysis was deleted each time to reflect the influence of the individual data set on the pooled ORs. The corresponding pooled ORs were not materially changed, which confirmed the stability of our overall result.

Egger's test was conducted to assess the publication bias of the literature. The shape of funnel plots did not reveal any evidence of funnel plot asymmetry (Figure 7$)$. The statistical results still did not show publication bias ( $p=0.258$ for TLR4 Asp299Gly variant and $p=0.342$ for Thr399lle variant).

\section{Discussion}

TLRs are involved in innate immunity defense against microorganisms [26]. They are recognized as a link between innate and adaptive immunity and contribute to efficient combat of pathogens in the immune system [27]. Studies have shown that SNPs within TLR genes can cause altered susceptibility to disease $[28,29]$. TLR4 is a central player in the response to infection by Gram-negative bacteria and thus an important candidate inflammatory gene [30]. In recent years, the impact of TLR4 polymorphisms on multiple types of cancer has been considered [31, 32]. The most intensively highlighted ones are Asp299Gly and Thr399lle, which are usually co-segregated [33]. However, the results from different published studies have been inconsistent. Thus, we performed this meta-analysis to comprehensively analyze their associations.

In this meta-analysis, we selected a total of 9 articles. For TLR4 Asp299Gly polymorphism, 
9 studies were selected to assess the association between Asp299Gly polymorphism and CRC risk. In the overall analysis, we observed that the GG genotype carriers had higher risk for developing CRC than AA + GA genotype carriers $(p=0.05)$. No association was found in other genetic models. In terms of analyses stratified by race, no significant association was found between the Asp299Gly variant and increased risk of CRC in any genetic models among the Caucasian population and Asian population $(p>0.05)$. However, the genetic models of the Asian group had higher risk for developing CRC than the Caucasian group. The TLR4 Asp299Gly polymorphism results in an aspartic acid to glycine replacement at codon 299 (D299G). It has been most investigated in different types of cancer, with controversial results [34, 35]. Omrane et al. showed a positive link between variant T Asp299Gly and CRC patients [18], while Davoodi et al. found that variant TLR4 Asp299Gly is not associated with risk of CRC [17]. This polymorphism has a distinct distribution in different populations due to evolutionary pressure, which may change the functionality of the receptor and explain the discrepancies between the studies [3].

For the Thr399lle polymorphism, a total of 6 articles were retrieved in our study. The overall analysis showed significantly increased risk in TT homozygote carriers in the recessive model compared to CC homozygotes ( $p=0.01)$ and C carriers $(\mathrm{TC}+\mathrm{CC})(p=0.02)$. No association was observed in other models. When evaluating the effect of the polymorphism by ethnicity, we found a significant association in all genetic models among the Asian population, while no relationship was found among the Caucasian population. The Thr399lle polymorphism leads to a threonine to isoleucine exchange at codon 399 (T399I). Guo et al. demonstrated that TLR4 D299G and T399l polymorphisms are associated with reduced activation of nuclear factor- $\kappa \mathrm{B}(\mathrm{NF}-\kappa \mathrm{B})$ and pro-inflammatory cytokine expression [36]. These two variants of TLR4 disrupt the extracellular region in the ligand binding site of the receptor, and were associated with decreased responsiveness to LPS and an attenuated immune response causing secretion of low levels of pro-inflammatory cytokines [37]. Slattery et al. demonstrated that genetic variation in TLR4 may influence the development of colon cancer as well as influence survival after diagnosis of colon cancer [38]. However, in the Caucasian population, there is no significant difference between CRC subjects and controls for T399I genotypes, suggesting that TLR4 polymorphisms may have an ethnicity-specific association with susceptibility to CRC.

TLR4 activation affects the immune response against invading Gram-negative bacteria, and is involved in chronic inflammation, autoimmune

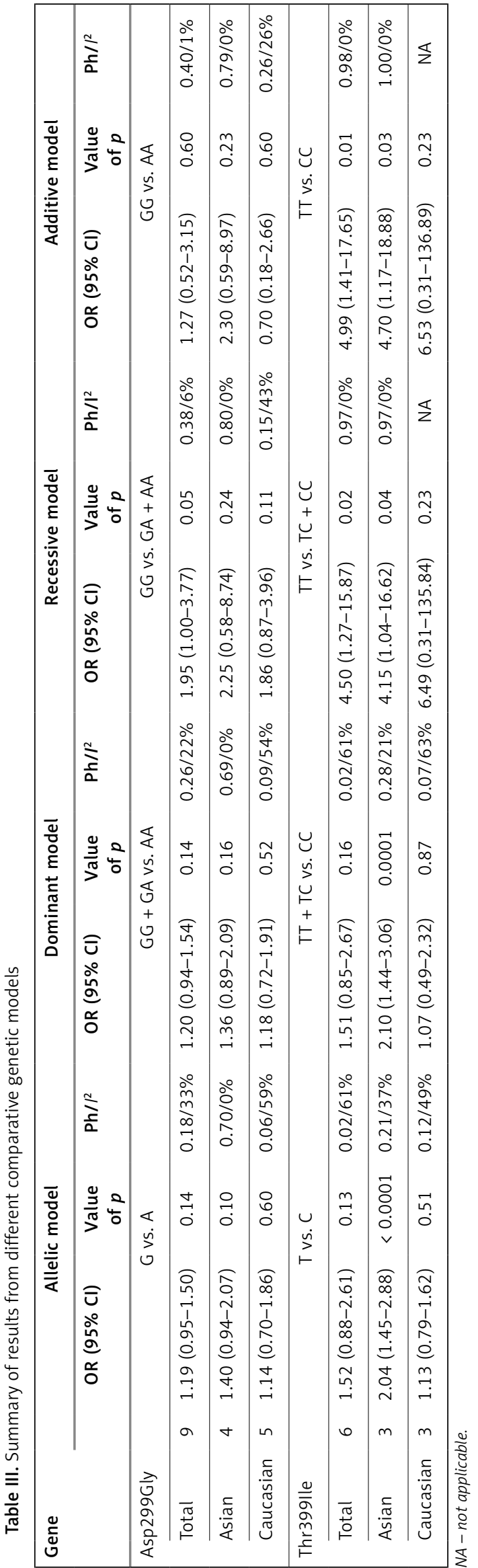




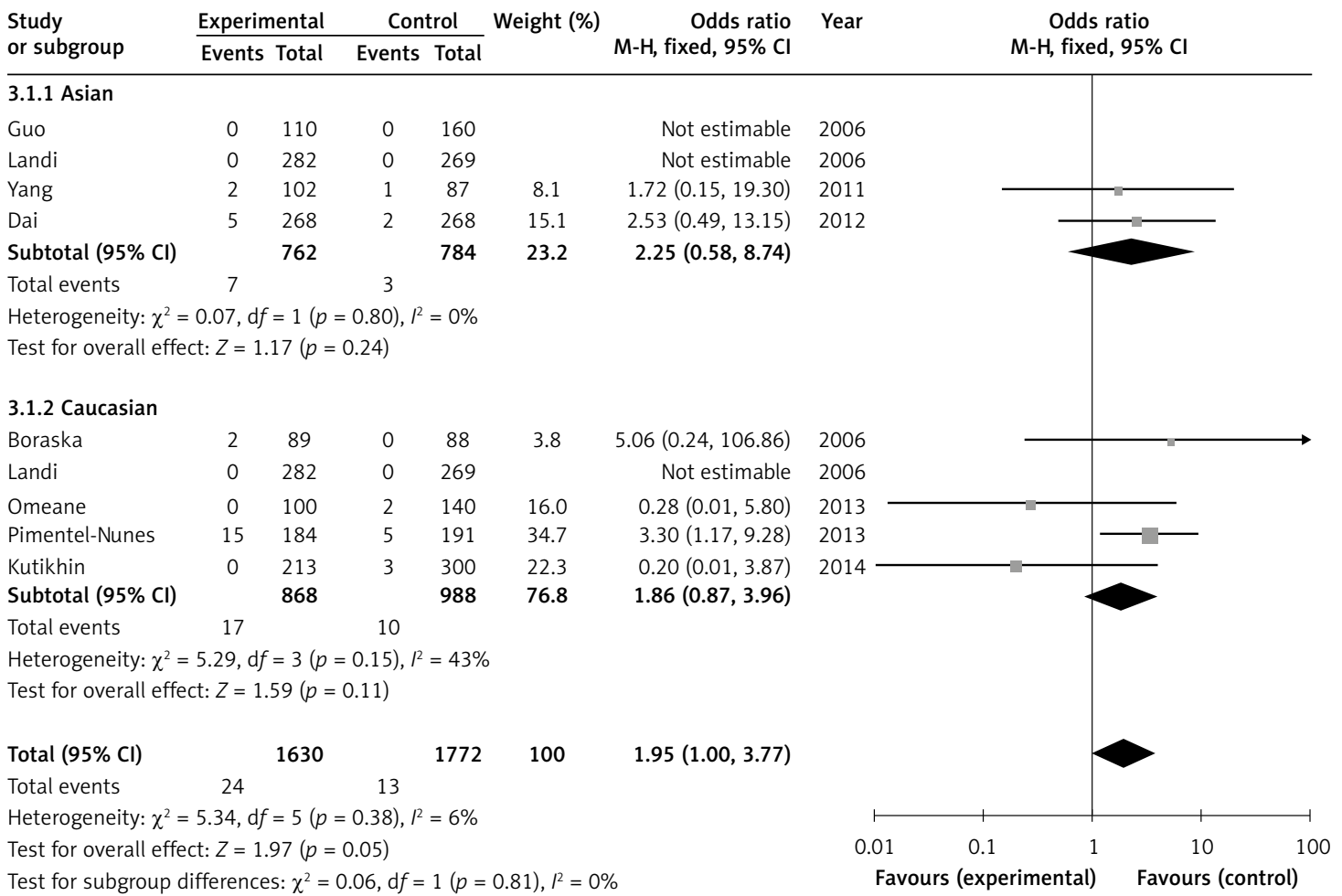

Figure 2. Forest plot of odds ratios (ORs) of TLR4 Asp299Gly polymorphism (GG vs. GA + AA) associated with CRC stratified by ethnicity

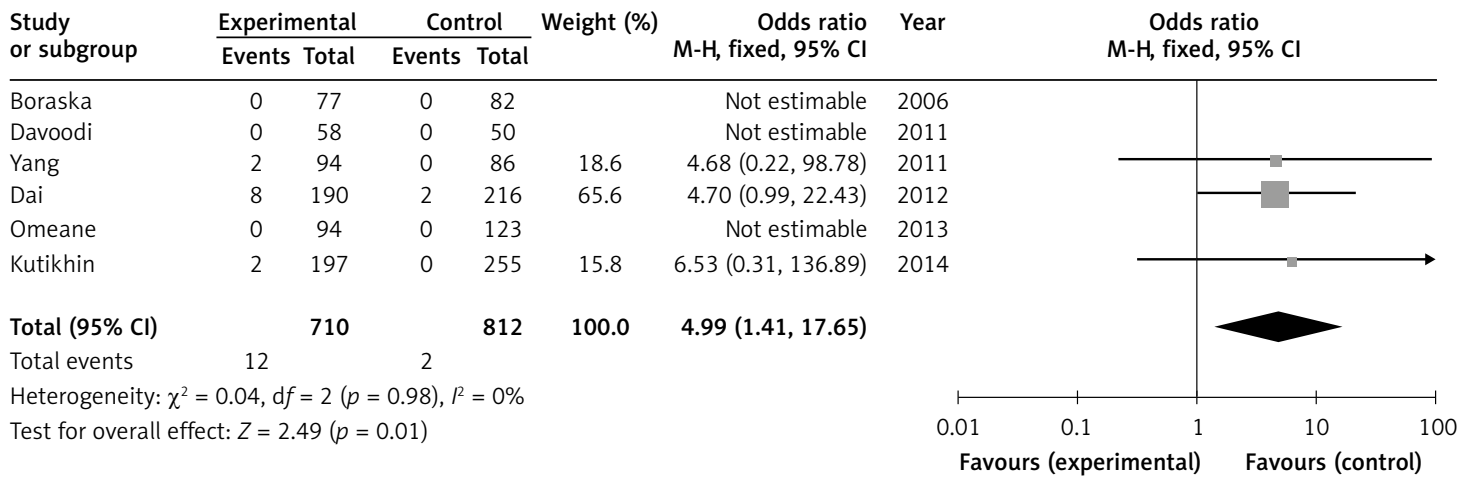

Figure 3. Forest plot of odds ratios (ORs) of TLR4 Thr399lle polymorphism (TT vs. CC) associated with CRC risk

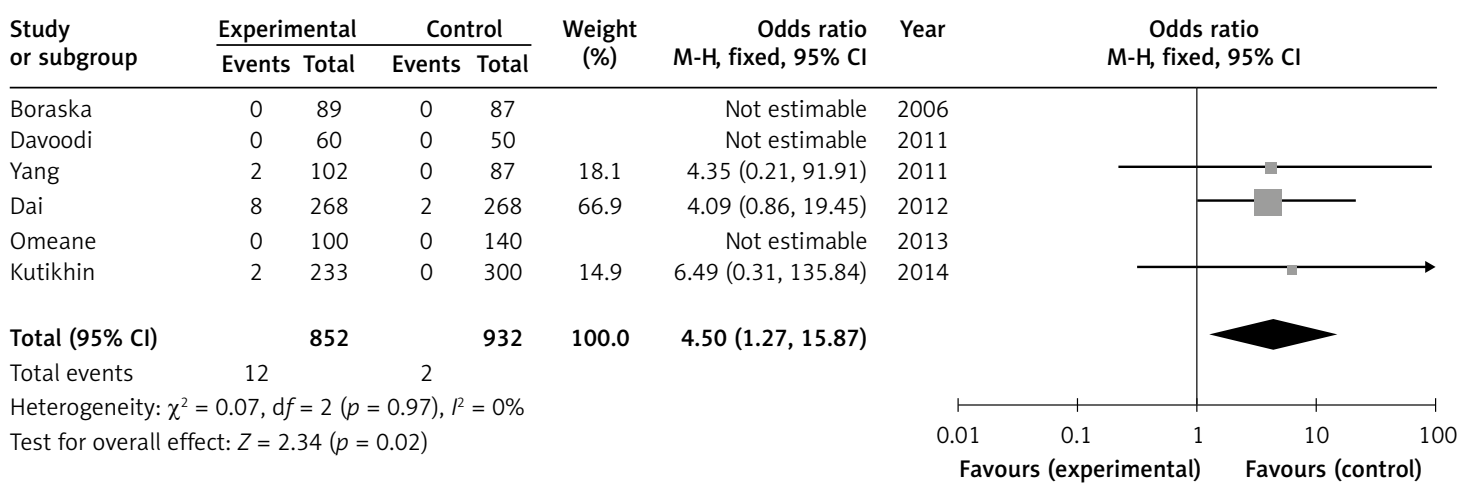

Figure 4. Meta-analysis of TLR4 Thr399lle polymorphism (TT vs. TC + CC) with risk of CRC 


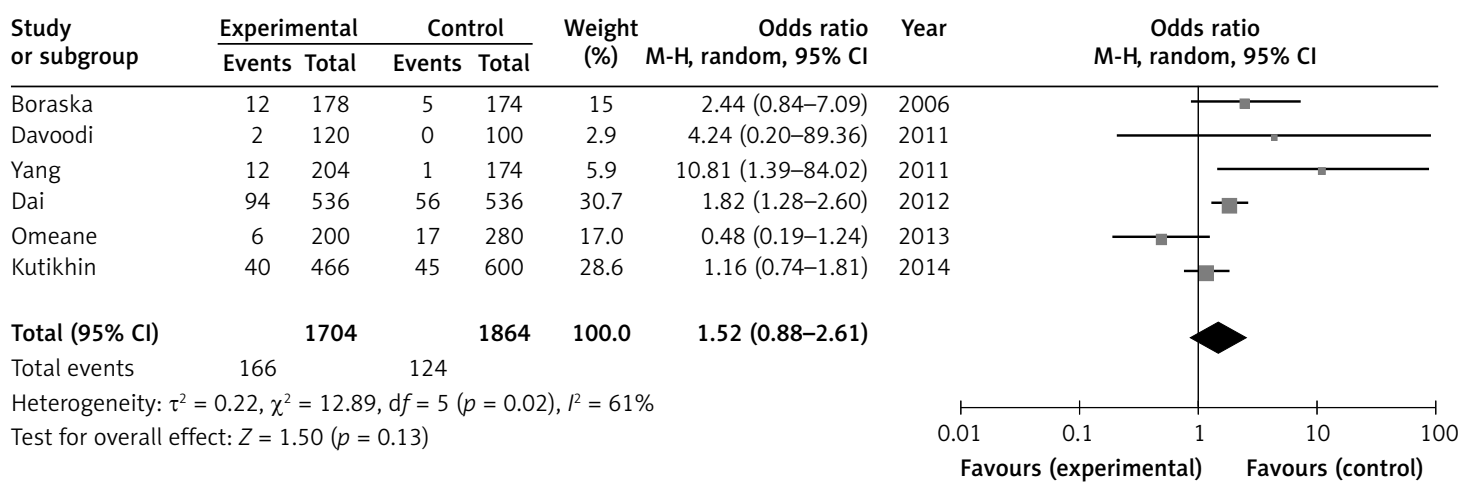

Figure 5. Forest plot of CRC associated with distribution of TLR4 Thr399lle polymorphism (TT + TC vs. CC) by stratified analysis

\begin{tabular}{|c|c|c|c|c|c|c|c|c|c|c|}
\hline \multirow{2}{*}{$\begin{array}{l}\text { Study } \\
\text { or subgroup }\end{array}$} & \multicolumn{2}{|c|}{ Experimental } & \multicolumn{2}{|c|}{ Control } & \multirow{2}{*}{$\begin{array}{c}\text { Weight } \\
\text { (\%) }\end{array}$} & \multirow{2}{*}{$\begin{array}{r}\text { Odds ratio } \\
\mathrm{M}-\mathrm{H}, \text { random, } 95 \% \mathrm{Cl}\end{array}$} & \multirow[t]{2}{*}{ Year } & \multirow{2}{*}{\multicolumn{2}{|c|}{$\begin{array}{c}\text { Odds ratio } \\
\mathrm{M}-\mathrm{H} \text {, random, } 95 \% \mathrm{Cl}\end{array}$}} & \\
\hline & Events & Total & Events & Total & & & & & & \\
\hline Boraska & 12 & 89 & 5 & 87 & 15.4 & $2.56(0.86,7.59)$ & 2006 & & & \\
\hline Davoodi & 2 & 60 & 0 & 50 & 3.2 & $4.32(0.20,92.02)$ & 2011 & & & \\
\hline Yang & 10 & 102 & 1 & 87 & 6.2 & $9.35(1.17,74.57)$ & 2011 & & & \\
\hline Dai & 86 & 268 & 54 & 268 & 29.8 & $1.87(1.26,2.78)$ & 2012 & & -- & \\
\hline Omeane & 6 & 100 & 17 & 140 & 17.4 & $0.46(0.18,1.22)$ & 2013 & & & \\
\hline Kutikhin & 38 & 233 & 45 & 300 & 28.1 & $1.10(0.69,1.77)$ & 2014 & & - & \\
\hline Total $(95 \% \mathrm{Cl})$ & & 852 & & 932 & 100.0 & $1.51(0.85,2.67)$ & & & & \\
\hline Total events & 154 & & 122 & & & & & & & \\
\hline \multicolumn{9}{|c|}{ Heterogeneity: $\tau^{2}=0.25, \chi^{2}=12.90, \mathrm{~d} f=5(p=0.02), I^{2}=61 \%$} & & \\
\hline \multirow{2}{*}{\multicolumn{7}{|c|}{ Test for overall effect: $Z=1.41(p=0.16)$}} & 0.01 & 0.1 & 10 & 100 \\
\hline & & & & & & & \multicolumn{4}{|c|}{ Favours (experimental) Favours (control) } \\
\hline
\end{tabular}

Figure 6. Association between T allele of TLR4 Thr399lle polymorphism and CRC risk

diseases, and malignancies as well [39]. It may be exploited by bacterial toxins to gain access and entry into cells [40]. The TLR4 gene exhibits a differential pattern of expression not only between coronary artery disease patients and controls in this Asian Indian cohort [41], but also in CRC. Wang et al. suggest that high expression of TLR4 is associated with liver metastasis and is an independent predictor of poor prognosis in patients with CRC [42], while Nihon-Yanagi et al. find that TLR4 expression might not be involved in sporadic colorectal carcinogenesis [43]. A study proved that TLR4 D299G induces features of neoplastic progression in intestinal epithelial Caco-2 cells and associates with aggressive colon cancer in humans, implying a novel link between aberrant innate immunity and colonic cancerogenesis [44]. The TLR4 variant D299G promotes inflammation-associated colon cancer progression in the intestinal epithelium [45]. The role of Toll-like receptors in renal diseases has been discussed by Gluba et al. [46].

Several limitations of this meta-analysis should be addressed. Firstly, the original information was insufficient, so assessment of potential interactions is limited. Secondly, the subgroups may have a relatively low power based on a small number of studies. Thirdly, a more precise analysis should be conducted if individual information including other covariates such as age, sex and

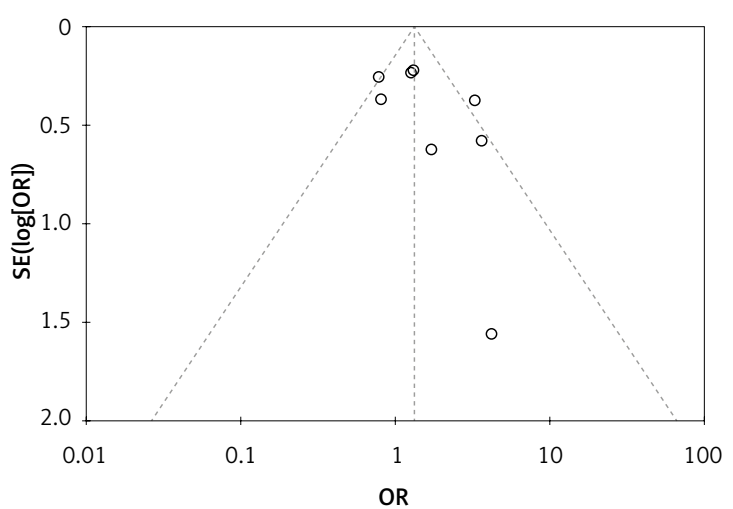

Figure 7. Begg's funnel plot for publication bias in selection of studies

smoking condition becomes available. Fourthly, the gene-gene interaction is important for the development of complex diseases including cancer [47].

In conclusion, the results from the present meta-analysis suggest that the GG genotype of TLR4 Asp299Gly and the TT genotype of TLR4 Thr399lle polymorphisms might be correlated with an increased risk of CRC, indicating that they may serve as biomarkers of disease progression. However, further large, well-designed, comprehensive studies in various populations are needed to confirm our results. Furthermore, studies of gene-gene and gene-environment interactions be- 
tween these polymorphisms and CRC risk should also be performed and considered.

\section{Conflict of interest}

The authors declare no conflict of interest.

\section{References}

1. Pagès F, Galon J, Fridman WH. The essential role of the in situ immune reaction in human colorectal cancer J Leukoc Biol 2008; 84: 981-7.

2. Jemal A, Bray F, Center MM, Ferlay J, Ward E, Forman D. Global cancer statistics. CA Cancer J Clin 2011; 61: 69-90.

3. Center MM, Jemal A, Ward E. International trends in colorectal cancer incidence rates. Cancer Epidemiol Biomarkers Prev 2009; 18: 1688-94.

4. Chang GJ, Hu CY, Eng C, et al. Practical application of a calculator for conditional survival in colon cancer. J Clin Oncol 2009; 27: 5938-43.

5. Lindstrom LS, Hall P, Hartman M, Wiklund F, Grönberg $\mathrm{H}$, Czene K. Familial concordance in cancer survival: a Swedish population-based study. Lancet Oncol 2007; 8: 1001-6.

6. Abuli A, Lozano JJ, Rodríguez-Soler M, et al. Genetic susceptibility variants associated with colorectal cancer prognosis. Carcinogenesis 2013; 34: 2286-91.

7. Abreu MT. Toll-like receptor signalling in the intestinal epithelium: how bacterial recognition shapes intestinal function. Nat Rev Immunol 2010; 10: 131-44.

8. Triantafilou M, Triantafilou K. Lipopolysaccharide recognition: CD14, TLRs and the LPS-activation cluster. Trends Immunol 2002; 23: 301-4.

9. Iwasaki A, Medzhitov R. Regulation of adaptive immunity by the innate immune system. Science 2010; 327: 291-5.

10. Wang RF, Miyahara Y, Wang HY. Toll-like receptors and immune regulation: implications for cancer therapy. Oncogene 2008; 27: 181-9.

11. Kurowski M, Majkowska-Wojciechowska B, Wardzyńska A, Kowalski ML. Associations of allergic sensitization and clinical phenotypes with innate immune response genes polymorphisms are modified by house dust mite allergen exposure. Arch Med Sci 2011; 7: 1029-36.

12. Zou TH, Wang ZH, Fang JY. Positive association between Toll-like receptor 4 gene+ 896A/G polymorphism and susceptibility to gastric carcinogenesis: a meta-analysis. Tumor Biology 2013; 34: 2441-50.

13. Shen X, Shi R, Zhang H, Li K, Zhao Y, Zhang R. The Tolllike receptor 4 D299G and T399l polymorphisms are associated with Crohn's disease and ulcerative colitis: a meta-analysis. Digestion 2010; 81: 69-77.

14. Wang XQ, Zhang K, Xiong D. Toll-like receptor 4 polymorphisms and susceptibility to multiple autoimmune diseases: evidence based on pooled analysis. Cent Eur J Immunol 2013; 38: 380-7.

15. Ferwerda B, McCall MB, Verheijen K, et al. Functional consequences of toll-like receptor 4 polymorphisms. Mol Med 2008; 14: 346-52.

16. Salanti G, Amountza G, Ntzani EE, loannidis JP. HardyWeinberg equilibrium in genetic association studies: an empirical evaluation of reporting, deviations, and power. Eur J Hum Genet 2005; 13: 840-8.

17. Davoodi H, Seow HF. Variant Toll-like receptor4 (Asp299Gly and Thr399lle alleles) and Toll-like receptor2
(Arg753Gln and Arg677Trp alleles) in colorectal cancer. Iran J Allergy Asthma Immunol 2011; 10: 91-9.

18. Omrane I, Baroudi O, Kourda N, et al. Positive link between variant Toll-like receptor 4 (Asp299Gly and Thr399lle) and colorectal cancer patients with advanced stage and lymph node metastasis. Tumour Biol 2014; 35: 545-51.

19. Pimentel-Nunes P, Teixeira AL, Pereira C, et al. Functional polymorphisms of Toll-like receptors 2 and 4 alter the risk for colorectal carcinoma in Europeans. Dig Liver Dis 2013; 45: 63-9.

20. Guo Q, Zhu J, Xia B. Polymorphism of CD14 gene but not the mutation of TLR4 gene is associated with colorectal cancer in Chinese patients. I Gastroenterol Hepatol 2006; 21: 92-7.

21. Dai X, Baroudi O, Kourda N, et al. Expression of IL-alpha and TNF-alpha modified by Toll-like receptor 4 genetic polymorphism is associated with colorectal carcinoma. Chin J Pathophysiol 2012; 28: 1976-8.

22. Yang G, et al. The single nucleotide polymorphisms of toll-like receptor 4 gene and colorectal cancer susceptibility. Chin J Gastrointest Surg 2011; 14: 814-5.

23. Boraska Jelavić T, et al. Microsatelite GT polymorphism in the toll-like receptor 2 is associated with colorectal cancer. Clin Genet 2006; 70: 156-60.

24. Kutikhin AG, et al. Correlation between genetic polymorphisms within IL-1B and TLR4 genes and cancer risk in a Russian population: a case-control study. Tumor Biology 2014; 1-10.

25. Landi S, Gemignani F, Bottari F, et al. Polymorphisms within inflammatory genes and colorectal cancer. J Negat Results Biomed 2006; 5: 15

26. Kawai T, Akira S. Toll-like receptors and their crosstalk with other innate receptors in infection and immunity. Immunity 2011; 34: 637-50.

27. Kawai T, Akira S. TLR signaling. Cell Death Differentiation 2006; 13: 816-25.

28. Liu F, et al. Frequency of TLR 2, 4, and 9 gene polymorphisms in Chinese population and their susceptibility to type 2 diabetes and coronary artery disease. Biomed Res Inter 2012; 2012.

29. Liadaki K, Petinaki E, Skoulakis C, et al. Toll-like receptor 4 gene (TLR4), but not TLR2, polymorphisms modify the risk of tonsillar disease due to Streptococcus pyogenes and Haemophilus influenzae. Clin Vaccine Immunol 2011; 18: 217-22.

30. Lee SO, Brown RA, Kang SH, Abdel Massih RC, Razonable RR. Toll-like receptor 4 polymorphisms and the risk of Gram-negative bacterial infections after liver transplantation. Transplantation 2011; 92: 690-6.

31. Zhu L, Yuan H, Jiang T, et al. Association of TLR2 and TLR4 polymorphisms with risk of cancer: a meta-analysis. PLoS One 2013; 8: e82858.

32. Zhang K, Zhou B, Wang Y, Rao L, Zhang L. The TLR4 gene polymorphisms and susceptibility to cancer: a systematic review and meta-analysis. Eur J Cancer 2013; 49: 946-54

33. Notarangelo L, Casanova JL, Conley ME, et al. Primary immunodeficiency diseases: an update from the International Union of Immunological Societies Primary Immunodeficiency Diseases Classification Committee Meeting in Budapest, 2005. J Allergy Clin Immunol 2006; 117: 883-96.

34. Vuononvirta J, Peltola V, Mertsola J, He O. Risk of repeated Moraxella catarrhalis colonization is increased in children with Toll-like receptor 4 Asp299Gly polymorphism. Pediatr Infect Dis J 2013; 32: 1185-8. 
35. Pulido I, Leal M, Genebat M, et al. The TLR4 ASP299GLY polymorphism is a risk factor for active tuberculosis in Caucasian HIV-infected patients. Curr HIV Res 2010; 8: 253-8.

36. Guo J, Loke J, Zheng F, et al. Functional linkage of cirrhosis-predictive single nucleotide polymorphisms of toll-like receptor 4 to hepatic stellate cell responses. Hepatology 2009; 49: 960-8.

37. Arbour NC, Lorenz E, Schutte BC, et al. TLR4 mutations are associated with endotoxin hyporesponsiveness in humans. Nat Genet 2000; 25: 187-91.

38. Slattery ML, Herrick JS, Bondurant KL, et al. Toll-like receptor genes and their association with colon and rectal cancer development and prognosis. Int I Cancer 2012; 130: 2974-80

39. Oblak A, Jerala R. Toll-like receptor 4 activation in cancer progression and therapy. J Immunol Res 2011; 2011.

40. Torgersen ML, Engedal N, Pedersen AM, et al. Toll-like receptor 4 facilitates binding of Shiga toxin to colon carcinoma and primary umbilical vein endothelial cells. FEMS Immunol Med Microbiol 2011; 61: 63-75.

41. Maitra A, Shanker J, Dash D, Arvind P, Kakkar VV. Understanding the expression of Toll-like receptors in Asian Indians predisposed to coronary artery disease. Arch Med Sci 2011; 7: 781-7.

42. Wang E, Qian ZR, Nakasono M, et al. High expression of Toll-like receptor 4 /myeloid differentiation factor 88 signals correlates with poor prognosis in colorectal cancer. Br J Cancer 2010; 102: 908-15.

43. Nihon-Yanagi Y, Terai K, Murano T, Matsumoto T, Okazumi S. Tissue expression of Toll-like receptors 2 and 4 in sporadic human colorectal cancer. Cancer Immunol Immunother 2012; 61: 71-7.

44. Eyking A, Ey B, Rünzi M, et al. Toll-like receptor 4 variant D299G induces features of neoplastic progression in Caco-2 intestinal cells and is associated with advanced human colon cancer. Gastroenterology 2011; 141: 2154-65.

45. Eyking A, et al. The Toll-like receptor (TLR) 4 variant D299G promotes inflammation-associated colon cancer progression in the intestinal epithelium: P-246. Inflamm Bowel Dis 2011; 17: S84.

46. Gluba A, Banach M, Hannam S, et al. The role of Toll-like receptors in renal diseases. Nat Rev Nephrol 2010; 6: 224-35.

47. Liu L, Wu C, Wang Y, et al. Association of candidate genetic variations with gastric cardia adenocarcinoma in Chinese population: a multiple interaction analysis. Carcinogenesis 2011; 32: 336-42. 